IZA DP No. 3127

Cooperative Household Models

Patricia Apps

Ray Rees

October 2007 


\title{
Cooperative Household Models
}

\author{
Patricia Apps \\ University of Sydney \\ and IZA \\ Ray Rees \\ University of Munich
}

\section{Discussion Paper No. 3127 \\ October 2007}

\author{
IZA \\ P.O. Box 7240 \\ 53072 Bonn \\ Germany \\ Phone: +49-228-3894-0 \\ Fax: +49-228-3894-180 \\ E-mail: iza@iza.org
}

\begin{abstract}
Any opinions expressed here are those of the author(s) and not those of the institute. Research disseminated by IZA may include views on policy, but the institute itself takes no institutional policy positions.

The Institute for the Study of Labor (IZA) in Bonn is a local and virtual international research center and a place of communication between science, politics and business. IZA is an independent nonprofit company supported by Deutsche Post World Net. The center is associated with the University of Bonn and offers a stimulating research environment through its research networks, research support, and visitors and doctoral programs. IZA engages in (i) original and internationally competitive research in all fields of labor economics, (ii) development of policy concepts, and (iii) dissemination of research results and concepts to the interested public.
\end{abstract}

IZA Discussion Papers often represent preliminary work and are circulated to encourage discussion. Citation of such a paper should account for its provisional character. A revised version may be available directly from the author. 
IZA Discussion Paper No. 3127

October 2007

\section{ABSTRACT}

\section{Cooperative Household Models}

We set out a general framework for cooperative household models, based on Samuelson's idea of a household welfare function, but extending it to incorporate the key insight from Nash bargaining models - the idea that the household's preference ordering over the utility profiles of its members depends on their wage rates (or prices more generally) and non-wage incomes. Applying reasonable general restrictions on the effects of changes in these variables allows derivation of the general implications of cooperative models.

JEL Classification: D10

Keywords: generalisation, household, model

Corresponding author:

Patricia Apps

Faculty of Law

The University of Sydney

173 - 175 Phillip Street

Sydney, NSW 2000

Australia

E-mail:P.Apps@usyd.edu.au 


\section{Introduction}

In his classic paper on community indifference curves, ${ }^{1}$ Samuelson noted that his proof that these indifference curves could not exist, in the sense that they constitute a preference map with the same properties as that in the standard individual consumer model, presented a problem for the theory of consumer demand. Observed household demands must in general be aggregates of the demands of the individuals in the household, but if social indifference curves do not exist, how can a household, thought of as a small society or economy, possess a preference ordering with the properties required to ensure well-behaved household demand functions?

Samuelson's solution was to assume that the household is able to achieve a sufficient degree of "cooperation and consensus" that its choices can be modelled as if it maximised a Bergson-Samuelson social welfare function (SWF), which in the present context we call the Household Welfare Function (HWF). Given the uility function $u_{i}\left(x^{i}\right)$ of the $i$ 'th household member, with $x^{i} \in \mathbf{R}_{+}^{m}$ her consumption bundle, this can be written as

$$
H=H\left(u_{1}\left(x^{1}\right), u_{2}\left(x^{2}\right), \ldots, u_{n}\left(x^{n}\right)\right)
$$

This function is strictly increasing in the utilities of the household members (the Pareto property), quasiconcave and differentiable to any required order. By analogy with the SWF, it abstracts from the process by which the household consensus is reached, and is to be used to explore the implications of any particular set of assumptions about the household's preference ordering over the utilities of its members. As Samuelson puts it in his discussion of social welfare functions in the context of the economy as a whole ${ }^{2}$

Without inquiring into its origins, we take as a starting point for our discussion a function of all the economic magnitudes of a system which is supposed to characterize some ethical belief $[\ldots . .$. Any possible opinion is permissible [...] We only require that the belief is such as to admit of an unequivocal answer as to whether one configuration of the economic system is "better" or "worse" than any other, or "indifferent", and that these relationships are transitive [.... numerous individuals find it of interest to specialize the form of [the SWF]

and indeed writing the function's arguments as utilities is one such specialization, since it could also more generally be written as a function of the consumption vectors themselves.

Writing the household budget constraint as $p x \leq \mu$, where $x=\sum_{i} x^{i}$ is the household's aggregate demand vector, $p \in \mathbf{R}_{++}^{m}$ a price vector and $\mu$ the household's aggregate non-wage income, Samuelson showed that solving the problem

\footnotetext{
${ }^{1}$ Samuelson (1956).

${ }^{2}$ Samuelson (1947) pp. 221, 222.
} 
of maximising $H$ subject to this budget constraint yielded well-behaved aggregate household demand functions $x(p, \mu)$. The value function of the problem, say $V(p, \mu)$, can be interpreted as the indirect utility function of a fictitious representative individual, from which a household utility function $U(x)$ can be derived in the usual way. Then, in the space of aggregate consumptions, the household can be represented as if it were an individual solving the problem $\left\{\max _{x} U(x)\right.$ s.t. $\left.p x \leq \mu\right\}$, yielding aggregate demands with all the standard properties, and in particular a symmetric, negative semidefinite Slutsky matrix.

Samuelson also showed that if $v^{i}\left(p, s_{i}\right)$ is the indirect utility function of a household member with arbitrary income $s_{i}$, the solution of the problem ${ }^{3}$

$$
\max _{s_{i}} H\left(v^{1}\left(p, s_{1}\right), v^{2}\left(p, s_{2}\right), \ldots, v^{n}\left(p, s_{n}\right)\right) \text { s.t. } \sum_{i=1}^{n} s_{i} \leq \mu
$$

yields functions $s_{i}(p, \mu)$, which he called the sharing rule, such that if each household member solves the problem $\left\{\max u_{i}\left(x^{i}\right)\right.$ s.t. $\left.p x^{i} \leq s_{i}(p, \mu)\right\}$, the resulting solution is identical to that of the original problem of maximising $H$ (.) subject to the household's budget constraint. This can be thought of as a form of two-stage budgeting: given the weak separability among the individual consumption vectors in $H($.$) , the household can be thought of as first optimally$ allocating its total expenditure among its members, and then allowing each member to choose the optimal allocation of her consumption expenditure among goods.

We find it useful, given the literature we will be discussing in the following sections, to specialise the above general model to a simple labour supply model for a two-person household. Thus let the consumption vector of individual $i=1,2$ be $\left(x_{i}, l_{i}\right)$, where $x$ is a Hicksian composite consumption commodity with price normalised at 1 , and $l$ is leisure measured in units of time. We normalise total time available at 1 and so $1-l_{i}$ is market labour supply. The price of leisure is the wage rate $w_{i}$ and $\mu_{i}$ is $i$ 's non-wage income. The HWF is now $H\left(u^{1}\left(x_{1}, l_{1}\right), u^{2}\left(x_{2}, l_{2}\right)\right)$ and the budget constraint is $\sum_{i}\left(x_{i}+w_{i} l_{i}\right) \leq$ $\sum_{i}\left(w_{i}+\mu_{i}\right){ }^{4}$

\section{Anonymity and Symmetry}

Samuelson clearly felt confident that he had given a satisfactory solution to the problem he had posed. Why was this solution apparently rejected by most of

\footnotetext{
${ }^{3} \mathrm{We}$ are free to choose representations of the utility functions such that $H$ is strictly quasiconcave in the $s_{i}$, so that no problems arise with second order conditions.

${ }^{4}$ Thus the models in this paper are based on the simple division of time use between market work and leisure. For a number of reasons, we regard it as essential for both theoretical and empirical applications of household models to extend this to include time spent in household production, as we did for example in Apps and Rees (1988), (1996), (1997). However, since in this paper we are concerned purely with the specification of the cooperative household's objective function, to focus on this issue we stay with the more restricted categorisation of time use.
} 
the subsequent contributors to the literature on family decision taking? ${ }^{5}$ One reason put forward ${ }^{6}$ was that Samuelson's approach misses the elements of conflict as well as cooperation that characterise household decision taking. This is not correct. Samuelson's formulation is quite general as to the processes that generate the HWF, and these may well involve conflict. The HWF simply represents the outcome of its resolution, a characterisation of the consensus that is ultimately achieved. McElroy and Horney, in motivating their Nash bargaining approach, ${ }^{7}$ argued that Samuelson's solution implies that the outcomes of family decisions are "empirically indistinguishable from those of constrained utility maximisation" in the individual consumer model. This is the key point: In a sense Samuelson's solution was too powerful in delivering a model that is too similar to the standard consumer model. In particular it has two results, the empirical support for which is heavily in doubt.

The first of these is anonymity: ${ }^{8}$ In Samuelson's model, an increment of income has the same effect regardless of the identity of the household member to whom that income accrues. A pure redistribution of income among household members has no effect on demands. Only aggregate income $\mu$ appears in the household demand functions. Against this there is now evidence that the identity of an income recipient or owner of assets matters in determining the household equilibrium. ${ }^{9}$

The second property is that of the symmetry of the Slutsky matrix of aggregate household demands. In the labour supply model of this paper, this implies that the compensated derivative of a wife's leisure demand (labour supply) with respect to the husband's wage be equal to that of the husband's leisure demand (labour supply) with respect to the wife's wage. A number of empirical studies also claim to show that this is also rejected. ${ }^{10}$ Although one can debate the conclusiveness of these empirical studies, we accept that these two results of Samuelson's model, anonymity and symmetry, are unlikely to be supported by the data.

\footnotetext{
${ }^{5}$ See for example Manser and Brown (1980), McElroy and Horney (1981) and Lundberg and Pollak (1993).

${ }^{6}$ See Manser and Brown (1980).

${ }^{7}$ See McElroy and Horney (1981).

${ }^{8}$ This is usually referred to in the literature, misleadingly in our view, as the "pooling hypothesis". Constraining household expenditure not to exceed total (pooled) household income is neither necessary nor sufficient to obtain this result.

${ }^{9}$ For example Lundberg, Pollak and Wales (1997) found that when a state transfer was paid to wives rather than husbands, family expenditure on women's and children's clothing showed a small but significant increase. See Thomas (1990) and Schultz (1990) for the early work, based on developing countries, also rejecting anonymity.

${ }^{10}$ See Fortin and Lacroix (1997), and the useful survey by Vermeulen (2002). A problem with this literature is that it ignores the evidence from time use studies that significant amounts of individuals' time are spent in household production. This raises severe doubts about the general validity of the results.
} 


\section{Nash Bargaining}

The Nash bargaining approach proceeds as follows. If the individuals behave cooperatively in allocating their time and income within the household they will achieve utilities $u^{i}\left(x_{i}, l_{i}\right)$, while if they behave non-cooperatively they will achieve indirect utilities $v_{i}^{0}\left(w_{i}, \mu_{i}\right)$, and these form the disagreement points or threat points in the Nash bargaining game. The exact rationalisation of these threat points varies in the literature. The early papers by Manser and Brown and McElroy and Horney saw these as being the utility levels the individuals could achieve in the best alternative to the household in question, what have come to be called "divorce threat points". ${ }^{11}$ Ulph (1988), Woolley (1988), Lundberg and Pollak (1993) and Chen and Woolley (2001) argue instead that these should be based on non-cooperative (Nash equilibrium) behaviour within an ongoing household. For present purposes we can remain agnostic on this point. The two key assumptions are that the threat point utilities are functions of own-wage rates and non-wage incomes, ${ }^{12}$ and that there exist cooperative household allocations that yield strictly higher utility levels for both individuals than these threat point utilities. Thus there is a "marriage surplus", and the purpose of the Nash bargaining game is to determine the division of this surplus between the two individuals.

In this setting, the solution to the Nash bargaining problem can then be formulated in the usual way ${ }^{13}$ as solving the problem

$$
\begin{gathered}
\max _{x_{i} l_{i}} H^{N}=\left[u^{1}\left(x_{1}, l_{1}\right)-v_{1}^{0}\left(w_{1}, \mu_{1}\right)\right]\left[u^{2}\left(x_{2}, l_{2}\right)-v_{2}^{0}\left(w_{2}, \mu_{2}\right)\right] \\
\text { s.t. } \quad \sum_{i}\left(x_{i}+w_{i} l_{i}\right) \leq \sum_{i}\left(w_{i}+\mu_{i}\right)
\end{gathered}
$$

McElroy and Horney (1981), in the general goods setting, give a very thorough derivation and discussion of the implications of this model for demand behaviour, and McElroy (1990) discusses the empirical application of the model. Ott (1992) does the same for a model extended to include household production and labour supplies.

Now it is clear that the Nash maximand $H^{N}$ is a type of HWF. Its essential difference to Samuelson's formulation is that the individual wage rates and non-wage incomes enter the function as arguments. That is, if we write the generalised household welfare function (GHWF) as

$$
H=H\left(u^{1}\left(x_{1}, l_{1}\right), u^{2}\left(x_{2}, l_{2}\right), w_{1}, \mu_{1}, w_{2}, \mu_{2}\right)
$$

\footnotetext{
${ }^{11} v_{i}^{0}\left(w_{i}, \mu_{i}\right)$ can be thought of as the indirect utility function derived from the problem $\max u_{i}^{0}\left(x_{i}, l_{i}\right)$ s.t. $x_{i} \leq w_{i}\left(1-l_{i}\right)+\mu_{i}$, where $u_{i}^{0}($.$) is i$ 's utility function in this alternative household.

${ }^{12}$ As well as possibly other variables that McElroy (1990) termed "extrahousehold environmental variables" (EEP's), such as the ratio of men to women on the marriage market, divorce laws and features of the tax system. These can all affect the utility levels that could be achieved at the threat point. Here however we focus on just wage rates and non-wage incomes.

${ }^{13}$ Chen and Woolley take the case of weighted Nash bargaining, with exponents, summing to 1 , on the utility differences in the function $H^{N}$.
} 
it is clear that $H^{N}$ is a particular form of this function.

Viewed historically, from the standpoint of Samuelson's formulation, the key innovation of the bargaining models is to introduce wages (or prices more generally) and individual non-wage incomes into the HWF. This arose quite naturally out of the assumption about the process by which the allocation is found, and the consequent inclusion of threat points. However, it suggests an obvious generalisation: We can accept the idea that the household's preferences over the utility profiles of its members could be influenced by their wage rates and non-wage incomes, as well as other exogenous variables, without necessarily having to accept the specific formulation, or ethical position, implied by Nash bargaining. That is, we can simply work with the GHWF, or other specific formulations of it.

Similarly, if we take the "collective model" of Chiappori (1988), ${ }^{14}$ proposed as an alternative to the Nash bargaining model, this postulates a GHWF of the form $^{15}$

$$
H^{C}=\alpha\left(w_{1}, w_{2}, \mu\right) u^{1}\left(x_{1}, l_{1}\right)+\left[1-\alpha\left(w_{1}, w_{2}, \mu\right)\right] u^{2}\left(x_{2}, l_{2}\right)
$$

In social choice terms, this is a weighted utilitarian SWF, its main property being that it possesses zero inequality aversion: All utility pairs $\left(u_{1}, u_{2}\right)$ are equally good if they yield the same weighted sum, regardless of the inequality in the utility levels that they might represent. Again, this is a special case of a GHWF, which, in the Samuelson tradition, abstracts from the process by which an allocation or preference ordering is reached, and, to use his language, "expresses the opinion" that only the weighted sum of utilities matters. We are obviously free to accept or reject this opinion, and explore the implications of other forms for the GHWF, say with positive inequality aversion. More to the point, we could ask: What should be the essential properties of the GHWF and what are the implications of these for household resource allocations in general?

\section{The Generalized Household Welfare Function}

We define in this section the general properties assumed for the GHWF. In the next section we show their implications for the household labour supply model. It will be useful to illustrate the general discussion with reference to both the examples just given, the Nash bargaining model (NBM) and the collective model $(\mathrm{CM})$. We define the generalized Samuelson model by the problem ${ }^{16}$

\footnotetext{
${ }^{14}$ Chiappori (1988) adopts the simple labour supply setting of the present paper, while Browning and Chiappori (1998) work with a generalised goods model of the type set out in the Introduction.

${ }^{15}$ Note that the collective model does not distinguish between individual non-wage incomes, expressing the weight $\alpha$ as a function of total non-wage income $\mu$ alone. This implies that, as it stands, the model has no implications regarding anonymity.

${ }^{16}$ In the general notation of the consumption good model introduced initially, the problem is $\max _{x^{i}} H\left(u^{1}\left(x^{1}\right), \ldots, u^{n}\left(x^{n}\right) ; p, \mu_{1}, . ., \mu_{n}\right)$ s.t. $p \sum_{i} x^{i} \leq \sum_{i} \mu_{i}$. The results derived below for the labour supply model extend in an obvious way to this model.
} 


$$
\begin{gathered}
\max _{x_{i} l_{i}} H\left(u^{1}\left(x_{1}, l_{1}\right), u^{2}\left(x_{2}, l_{2}\right) ; w_{1}, \mu_{1}, w_{2}, \mu_{2}\right) \\
\text { s.t. } \quad \sum_{i}\left(x_{i}+w_{i} l_{i}\right) \leq \sum_{i}\left(w_{i}+\mu_{i}\right)+t
\end{gathered}
$$

Here $t$ is thought of as a transfer to the household that is not assigned to any one individual, and does not affect the household's preferences over utility profiles. It could of course be zero in any application, but it is a useful construct nonetheless, as we see below.

It is perhaps of interest to speculate on what Samuelson may have thought of this generalization. On the one hand, as the above quotation shows, he clearly conceived of social welfare functions in very general terms indeed. On the other hand, as part of the same discussion, he writes:

For one thing, prices are not usually included in the welfare function itself, except very indirectly through the effects of different prices and wages upon the quantities of consumption, work etc.

However, this exclusion is no doubt due to the fact that in the case of the economy as a whole, prices and wages are endogenous variables. Indeed, in applications of the social welfare function, for example in optimal tax theory, it is invariably written as a function of individual utilities alone. However, in the case of the household, wages and non-wage incomes are exogenous, and so an objection on grounds of endogeneity would not apply. We therefore propose the GHWF as the appropriate extension of the idea of a social welfare function to the case of the household.

The GHWF is assumed to possess the Pareto property and quasi-concavity with respect to the utility profile $\left(u^{1}(),. u^{2}().\right)$ for any given vector $\left[w_{1}, \mu_{1}, w_{2}, \mu_{2}\right]$, as well as differentiability. It is natural to place the further generic restrictions, which hold everywhere except possibly at special points in the domain:

A1: $H_{w_{i}}, H_{\mu_{i}} \neq 0, i=1,2$.

It is not possible to be more specific about the signs of these derivatives, as the examples of the NBM and CM show.

$N B M$ :

$$
H_{w_{i}}^{N}=-\lambda_{i}^{0}\left(1-l_{i}^{0}\right)\left(u^{j}-v_{j}^{0}\right) \quad i, j=1,2, \quad i \neq j
$$

where $l_{i}^{0}$ is the uncompensated leisure demand of individual $i$ at her threat point, and $\lambda_{i}^{0}$ is her marginal utility of income at that point. This is strictly negative at all points of interest, given a positive "marriage surplus", but zero at the points $u^{j}=v_{j}^{0}$ and $l_{i}^{0}=1$. For $\mu_{i}$ we have

$$
H_{\mu_{i}}^{N}=-\lambda_{i}^{0}\left(u^{j}-v_{j}^{0}\right) \quad i, j=1,2, \quad i \neq j
$$

which again is strictly negative at all points of interest, but zero at $u^{j}=v_{j}^{0}$. Note that this formalises an important point made by Lundberg and Pollak (1993), which led to the formulation of their "separate spheres" bargaining model: a 
pure redistribution of incomes between household members has no effect in the NBM if it leaves the threat points unchanged, i.e. if $\lambda_{i}^{0}=0$ for such a redistribution.

$C M$ :

$$
H_{w_{i}}^{C}=\alpha_{w_{i}}\left(u^{1}-u^{2}\right) \gtreqless 0
$$

Here $\alpha_{w_{1}}>0, \alpha_{w_{2}}<0$, and the sign of the derivative $H_{w_{i}}$ depends on the relationship between the two utility values, with zeroes at all allocations such that $u^{1}=u^{2}$. Likewise

$$
H_{\mu}^{C}=\alpha_{\mu}\left(u^{1}-u^{2}\right) \gtreqless 0
$$

More structure is introduced into the general model by assuming ${ }^{17}$ :

A2: $H_{i w_{i}}, H_{i \mu_{i}} \geq 0 \geq H_{i w_{j}}, H_{i \mu_{j}}, i, j=1,2 i \neq j$, where $H_{i w_{i}}\left(H_{i \mu_{i}}\right)$ and $H_{i w_{j}}\left(H_{i \mu_{j}}\right)$ cannot both be zero.

In words: at the margin, the weight the household places on an individual's welfare is always non-decreasing in her own wage and non-wage income, always non-increasing in those of the other individual, and at least one of these derivatives with respect to the wage (resp. to the non-wage income) is non-zero. This guarantees that all of these variables have a non-trivial effect on the equilibrium resource allocation, since they change the household's marginal rates of substitution between individual utilities at all points. Specifically, the conditions imply

$$
\begin{gathered}
\frac{\partial}{\partial w_{1}}\left[\frac{H_{1}}{H_{2}}\right], \frac{\partial}{\partial \mu_{1}}\left[\frac{H_{1}}{H_{2}}\right]>0 \\
\frac{\partial}{\partial w_{2}}\left[\frac{H_{1}}{H_{2}}\right], \frac{\partial}{\partial \mu_{2}}\left[\frac{H_{1}}{H_{2}}\right]<0
\end{gathered}
$$

where $H_{1} / H_{2}$ is the household's marginal rate of substitution between 1 and 2's utility in the $\left(u^{1}, u^{2}\right)$-plane. The household's indifference curves in this plane at any point steepen with increases in $w_{1}$ and $\mu_{1}$ and flatten with increases in $w_{2}$ and $\mu_{2}$. These restrictions imply that an increase in individual $i$ 's wage rate or non-wage income always increases $i$ 's relative weight in the GHWF.

As illustrations of these properties we have

NBM:

$$
\begin{aligned}
& H_{i}^{N}=u^{j}-v_{j}^{0} ; \quad H_{i w_{i}}^{N}=0 ; \quad H_{i w_{j}}^{N}=-\frac{\partial v_{j}^{0}}{\partial w_{j}}<0 \\
& H_{i \mu_{i}}^{N}=0 ; \quad H_{i \mu_{j}}^{N}=-\lambda_{j}^{0}<0 \quad i, j=1,2, \quad i \neq j
\end{aligned}
$$

$C M$ :

$$
\begin{gathered}
H_{1 w_{1}}^{C}=\alpha_{w_{1}}>0 ; \quad H_{1 w_{2}}^{C}=\alpha_{w 2}<0 \quad H_{2 w_{i}}^{C}=-H_{1 w_{i}}^{C} \quad i=1,2 . \\
-H_{2 \mu}^{C}=H_{1 \mu}^{C}=\alpha_{\mu} \gtreqless 0
\end{gathered}
$$

${ }^{17}$ Here, $H_{i} \equiv \partial H / \partial u^{i}$. 


\section{The GHWF and Labour Supplies}

The restrictions on household labour supply functions implied by Samuelson's HWF are identical to those in a standard individual consumer model. This changes dramatically when we move to a GHWF with the above general properties. It turns out that, as we should expect from Pollak's (1977) analysis of price-dependent preferences ${ }^{18}$, the Slutsky matrix in the household's labour supply problem cannot be shown to be symmetric and negative semidefinite. In defining the compensated derivatives, "compensation" of changes in wage rates and non-wage incomes must be understood as holding household welfare, and not individual utilities, constant. Here we summarise and provide intuition for the main results, details are given in the Appendix.

Non-anonymity: the effect of a change in non-wage income will depend on the identity of the recipient of that income, and a pure income redistribution within the household will change labour supplies.

The simplest way to show this is to note that Samuelson's decentralisation proposition still applies, in that there is an identity between the labour supplies derived by solving the problem in (7), (8), and those derived by first solving the household's income distribution problem

$$
\begin{gathered}
\max _{s_{i}} H\left(v^{1}\left(w_{1}, s_{1}\right), v^{2}\left(w_{2}, s_{2}\right) ; w_{1}, \mu_{1}, w_{2}, \mu_{2}\right) \\
\text { s.t. } \quad \sum_{i} s_{i} \leq \sum_{i}\left(w_{i}+\mu_{i}\right)+t
\end{gathered}
$$

for the sharing rule functions $s_{i}\left(w_{1}, \mu_{1}, w_{2}, \mu_{2}, t\right)$, and then solving the individual utility maximisation problems

$$
\max _{x_{i} l_{i}} u^{i}\left(x_{i}, l_{i}\right) \text { s.t. } x_{i}+w_{i} l_{i} \leq s_{i}\left(w_{1}, \mu_{1}, w_{2}, \mu_{2}, t\right)
$$

yielding leisure demands $l_{i}\left(w_{i}, s_{i}\left(w_{1}, \mu_{1}, w_{2}, \mu_{2}, t\right)\right.$. It then follows that

$$
\frac{\partial l_{i}}{\partial \mu_{i}}=\frac{\partial l_{i}}{\partial s_{i}} \frac{\partial s_{i}}{\partial \mu_{i}} ; \quad \frac{\partial l_{i}}{\partial \mu_{j}}=\frac{\partial l_{i}}{\partial s_{i}} \frac{\partial s_{i}}{\partial \mu_{j}} \quad i, j=1,2, \quad i \neq j
$$

and standard comparative statics analysis shows that $\partial s_{i} / \partial \mu_{i} \neq \partial s_{i} / \partial \mu_{j}$, (see Part B of the Appendix).

(Non-)Symmetry of compensated labour supply derivatives:

We now derive necessary and sufficient conditions under which the compensated derivatives of $i$ 's labour supply with respect to $j$ 's wage will be equal, $i, j=1,2, \quad i \neq j$, and also show that these conditions do not in general hold in this model. To do so we take the dual of the problem in (19), (20):

$$
\min _{x_{i} l_{i}} t=\sum_{i}\left(x_{i}-w_{i}\left(1-l_{i}\right)-\mu_{i}\right)
$$

\footnotetext{
${ }^{18}$ This saw the reasons for including prices in an individual utility function as either Veblenesque "snob effects" or the use of prices as indicators of quality.
} 


$$
\text { s.t. } H\left(u^{1}\left(x_{1}, l_{1}\right), u^{2}\left(x_{2}, l_{2}\right) ; w_{1}, \mu_{1}, w_{2}, \mu_{2}\right) \geq H
$$

The solution to this problem yields an expenditure function $t\left(w_{1}, \mu_{1}, w_{2}, \mu_{2}, H\right)$, giving the unassigned income required to reach any given household welfare level. Applying the Envelope Theorem gives

$$
\frac{\partial t}{\partial w_{i}}=-\left(1-l_{i}\right)-\beta H_{w_{i}} \quad i=1,2
$$

where $\beta$ is a Lagrange multiplier. Then by Young's Theorem

$$
\begin{aligned}
\frac{\partial^{2} t}{\partial w_{j} \partial w_{i}} & =\frac{\partial l_{i}}{\partial w_{j}}-\beta H_{w_{i} w_{j}}-H_{w_{i}} \frac{\partial \beta}{\partial w_{j}} \\
& =\frac{\partial l_{j}}{\partial w_{i}}-\beta H_{w_{j} w_{i}}-H_{w_{j}} \frac{\partial \beta}{\partial w_{i}} \\
& =\frac{\partial^{2} t}{\partial w_{i} \partial w_{j}} \quad i, j=1,2, \quad i \neq j
\end{aligned}
$$

Thus we have that the necessary and sufficient conditions for the compensated leisure demand derivatives to be equal, i.e.

$$
\frac{\partial l_{1}}{\partial w_{2}}-\frac{\partial l_{2}}{\partial w_{1}}=H_{w_{1}} \frac{\partial \beta}{\partial w_{2}}-H_{w_{2}} \frac{\partial \beta}{\partial w_{1}}=0
$$

are:

$$
\text { (i) } H_{w_{i}} \equiv 0, \quad i=1,2
$$

or

$$
\text { (ii) } H_{w_{i}} \neq 0 \text { and } \frac{H_{w_{j}}}{H_{w_{i}}}=\frac{\partial \beta / \partial w_{j}}{\partial \beta / \partial w_{i}} \quad i, j=1,2, \quad i \neq j
$$

$(i)$ is of course ruled out by assumption, while we show in Part A of the Appendix that (ii) also does not in general hold.

Own-wage effects on compensated leisure demands/labour supplies:

We can show in the usual way that the expenditure function $t($.$) has the$ usual property of concavity in $\left(w_{1}, \mu_{1}, w_{2}, \mu_{2}\right)$, and so, using (25) we have

$$
\frac{\partial^{2} t}{\partial w_{i}^{2}}=\frac{\partial l_{i}}{\partial w_{i}}-\beta H_{w_{i} w_{i}}-H_{w_{i}} \frac{\partial \beta}{\partial w_{i}} \leq 0
$$

However, the signs of $\beta H_{w_{i} w_{i}}$ and $H_{w_{i}} \partial \beta / \partial w_{i}$ are in general indeterminate, and so we cannot conclude that $\partial l_{i} / \partial w_{i}<0$. The intuition is as follows. When $w_{i}$ increases, say, $i$ 's leisure becomes more expensive for the household, and so the usual substitution effect would work towards reducing it, but at the same time, her marginal weight in the GHWF increases, implying that she may be given a higher income share. This then increases her demand for leisure (assuming it is normal) and so could increase the household's demand for her leisure overall, even as a compensated effect. Clearly, this latter effect disappears if $H_{w_{i}} \equiv 0$, as in Samuelson's HWF model. 
More positively, we can place some testable restrictions on the compensated derivatives of the sharing rule, the functions $s_{i}($.$) . We do this by using the$ problem in (23), (24) to derive a type of Slutsky equation for these functions. By carrying out the standard comparative statics analysis for this problem we can show:

A compensated increase in i's non-wage income always increases her share and reduces $j$ 's.

Thus we have:

$$
\begin{gathered}
\frac{\partial s_{i}}{\partial \mu_{i}}=\frac{v_{s}^{i} H_{i \mu_{i}}-v_{s}^{j} H_{j \mu_{i}}}{\Delta}+\frac{\partial s_{i}}{\partial t} \quad i, j=1,2, \quad i \neq j \\
\frac{\partial s_{j}}{\partial \mu_{i}}=\frac{v_{s}^{j} H_{j \mu_{i}}-v_{s}^{i} H_{i \mu_{i}}}{\Delta}+\frac{\partial s_{j}}{\partial t} \quad i, j=1,2, \quad i \neq j
\end{gathered}
$$

where $\Delta>0$ is the bordered Hessian of the Lagrange function. From A2 we have that the first terms in these two equations are respectively positive and negative. These are the compensated effects in question, since the second term in each expression is an income effect, equivalent to the effect of a change in non-assigned income $t$ on the respective income shares. In general these income effects may be positive or negative. However, call a household fair if these income effects are both always positive. Then we have:

In a fair household, an uncompensated increase in i's non-wage income always increases her share and may increase or reduce $j$ 's.

The intuition for the latter ambiguity is of course that while the income effect of the increase in $\mu_{i}$ tends to increase $s_{j}$, the increase in the marginal weight the household places on $i$ 's utility tends to reduce it. Note that in Samuelson's HWF model both compensated terms are zero and only the income effect remains.

However, the effect of a compensated change in $i$ 's wage cannot be signed unambiguously:

$$
\begin{aligned}
& \frac{\partial s_{i}}{\partial w_{i}}=\frac{v_{s}^{i} H_{i w_{i}}-v_{s}^{j} H_{j w_{i}}}{D}+\frac{H_{i} v_{s w}^{i}}{D}+\frac{\partial s_{i}}{\partial t} \quad i, j=1,2, \quad i \neq j \\
& \frac{\partial s_{j}}{\partial w_{i}}=\frac{v_{s}^{j} H_{j w_{i}}-v_{s}^{i} H_{i w_{i}}}{D}-\frac{H_{i} v_{s w}^{i}}{D}+\frac{\partial s_{j}}{\partial t} \quad i, j=1,2, \quad i \neq j
\end{aligned}
$$

The ambiguity is created by the term $H_{i} v_{s w}^{i}$, which also arises in Samuelson's HWF model and has an interesting intuitive explanation. Holding the $s_{i}$ and the marginal household weights on individual utilities, $H_{i}$, constant, an increase say in 1's wage could cause a reduction in the marginal household utility derived from an additional dollar to 1 , thus changing the marginal rate of substitution between $s_{1}$ and $s_{2}$ along a household indifference curve, and leading cet. par. to an increase in $s_{2}$ and reduction in $s_{1}$. Note that Samuelson's problem in (2) already has preferences that are effectively price-dependent in the $\left(s_{1}, s_{2}\right)$-plane. 


\section{Conclusions}

In this paper we have set out a general framework for cooperative household models, based on Samuelson's idea of a household welfare function, but extending it to incorporate the key insight from the Nash bargaining models - the idea that the household's preference ordering over the utility profiles of its members depends on their wage rates (or prices more generally) and non-wage incomes. Applying what appear to be reasonable general restrictions on the effects of changes in these exogenous variables allows a straightforward derivation of the general implications of cooperative models, for the case of household labour supplies. By placing the existing specific models in this broader context, we hope to have suggested the possibility of other approaches to modelling household preferences, that depart from the special structure of these models.

The cooperative models discussed in this paper take an important step beyond the standard model of the individual consumer/worker, but still have the major limitation that they ignore the possible presence of children in the household, and continue to assume that time is divided simply between market labour supply and leisure, i.e. they ignore household production. These two points are closely related: the presence of children makes household production, including child care, a far more demanding and time-consuming activity than when they are absent. Two-person bargaining models obviously have difficulty in incorporating children as individual consumers and, possibly, participants in household decision taking, which perhaps explains why children are so often treated as household public goods "consumed" by their parents, or simply as "demographic variables" in empirical analysis. The GHWF approach, on the other hand, is easily extended to allow for the existence of more than two individuals, with their own utility functions, in the household, and can readily be complemented by a household production model..$^{19}$ It is hard to see how models which exclude children and household production are able to say much of interest about either within- or across-household welfare distribution, which, after all, is ultimately the main motivation for developing models of the multi-person household.

\section{References}

[1] Apps, P.F., \& Rees, R. (1988), "Taxation and the household", Journal of Public Economics, 35, 355-369.

[2] Apps, P.F., \& Rees, R. (1996). Labour supply, household production and intra-family welfare distribution. Journal of Public Economics 60, 199-219.

[3] Apps, P.F., \& Rees, R. (1997). Collective labor supply and household production. Journal of Political Economy 105, 178-190.

\footnotetext{
${ }^{19}$ For an example of this approach see Apps and Rees (2001).
} 
[4] Apps, P.F. and Rees, R. (2001). Household production, full consumption and the costs of children, Labour Economics, 8, 621-648.

[5] Browning, M., \& Chiappori, P.-A. (1998). Efficient intra-household allocation: a characterisation and tests. Econometrica, 66 (6), 1241-1278.

[6] Chen, Z., \& Woolley, F. (2001). A Cournot-Nash model of family decision making. Economic Journal, 111(474), 722-748.

[7] Chiappori, P.-A. (1988). Rational household labor supply. Econometrica, 56(1), 63-90.

[8] Fortin, B. \& Lacroix, G. (1997). A test of the unitary and collective models of household labour supply. Economic Journal, 107, 933-955.

[9] Lundberg, S., \& Pollak, R. A. (1993). Separate spheres bargaining and the marriage market. Journal of Political Economy, 101, 988-1010.

[10] Lundberg, S., Pollak, R. A. \& Wales, T. J. (1997). Do husbands and wives pool their resources? Evidence from the UK child benefit. Journal of Human Resources,32(3), 463-480.

[11] McElroy, M. B. \& and Horney, M. (1981). Nash-bargained decisions: Towards a generalization of the theory of demand. International Economic Review, 22, 333-349.

[12] McElroy, M. B. (1990). The empirical content of Nash bargained household behaviour. Journal of Human Resources, (25)4, 559-583.

[13] Manser, M., \& Brown, M. (1980). Marriage and household decision making: A bargaining analysis. International Economic Review, 21(1), 31-34.

[14] Ott, N., (1992). Intrafamily Bargaining and Household Decisions. Berlin: Springer-Verlag, .

[15] Pollak, R. A. (1977). Price dependent preferences. American Economic Review, 67, 64-75.

[16] Samuelson, P. A. (1947). Foundations of Economic Analysis. Cambridge, Mass: Harvard University Press.

[17] Samuelson, P. A. (1956). Social indifference curves. Quarterly Journal of Economics, 70, 1-22.

[18] Schultz, T. P. (1990). Testing the neoclassical model of family labour supply and fertility. Journal of Human Resources, 25, 599-634.

[19] Thomas, D. (1990). Intra-household resource allocation: An inferential approach. Journal of Human Resources, 25, 635-664. 
[20] Ulph, D. (1988). A general non-cooperative Nash model of household consumption behaviour. Working paper 88-205, Department of Economics, University of Bristol.

[21] Vermeulen, F. (2002). Collective household models: Principles and main results. Journal of Economic Surveys, 16, 533-564.

[22] Woolley, F. (1988). A non-cooperative model of family decision making. Discussion Paper TIDI 125, London School of Economics.

\section{Appendix}

Part A

The problem is

$$
\begin{gathered}
\min _{x_{i} l_{i}} t=\sum_{i}\left(x_{i}-w_{i}\left(1-l_{i}\right)-\mu_{i}\right) \\
\text { s.t. } H\left(u^{1}\left(x_{1}, l_{1}\right), u^{2}\left(x_{2}, l_{2}\right) ; w_{1}, \mu_{1}, w_{2}, \mu_{2}\right) \geq H
\end{gathered}
$$

first order conditions of which are

$$
\begin{array}{cc}
1-\beta H_{i} u_{x_{i}}^{i}=0 \quad i=1,2 \\
w_{i}-\beta H_{i} u_{l_{i}}^{i}=0 \quad i=1,2
\end{array}
$$

together with the constraint as an equality, with $\beta$ as a Lagrange multiplier. Standard comparative statics analysis then gives

$H_{w_{1}} \frac{\partial \beta}{\partial w_{2}}-H_{w_{2}} \frac{\partial \beta}{\partial w_{1}}=A \frac{D_{15}+w_{1} D_{25}}{H_{1} D}+B \frac{D_{35}+w_{2} D_{45}}{H_{2} D}+\frac{H_{w_{1}} D_{45}-H_{w_{2}} D_{25}}{D}$

where

$$
\begin{aligned}
& A=H_{w_{2}} H_{1 w_{1}}-H_{w_{1}} H_{1 w_{2}} \\
& B=H_{w_{2}} H_{2 w_{1}}-H_{w_{1}} H_{2 w_{2}}
\end{aligned}
$$

$D$ is the bordered Hessian of the Lagrangean, and $D_{i 5}, i=1, . ., 4$ is the corresponding cofactor of $D$. Then assumption A2 implies that $A$ and $B$ cannot be zero, and inspection of $D$ shows that the expression in (41) cannot be zero.

Part B

The problem

$$
\begin{gathered}
\max _{s_{i}} H\left(v^{1}\left(w_{1}, s_{1}\right), v^{2}\left(w_{2}, s_{2}\right) ; w_{1}, \mu_{1}, w_{2}, \mu_{2}\right) \\
\text { s.t. } \quad \sum_{i} s_{i} \leq \sum_{i}\left(w_{i}+\mu_{i}\right)+t
\end{gathered}
$$

has first order conditions

$$
H_{i} v_{s}^{i}-\lambda=0 \quad i=1,2
$$


together with the constraint as an equality, with $\lambda$ a Lagrange multiplier. Standard comparative statics analysis then gives

$$
\begin{aligned}
& \frac{\partial s_{i}}{\partial \mu_{i}}=\frac{H_{i \mu_{i}} v_{s}^{i}-H_{j \mu_{i}} v_{s}^{j}}{\Delta}+\frac{\partial s_{i}}{\partial t} \quad i, j=1,2, \quad i \neq j \\
& \frac{\partial s_{i}}{\partial \mu_{j}}=\frac{H_{i \mu_{j}} v_{s}^{i}-H_{j \mu_{j}} v_{s}^{j}}{\Delta}+\frac{\partial s_{i}}{\partial t} \quad i, j=1,2, \quad i \neq j
\end{aligned}
$$

where $\Delta>0$ is the bordered Hessian of the Lagrange function. Since assumption A2 implies $H_{i \mu_{i}} \neq H_{i \mu_{j}}$, these two cannot be equal. 